\title{
Reactivity of Gliadin and Lectins with Celiac Intestinal Mucosa ${ }^{1}$
}

\author{
K. PITTSCHIELER, B. LADINSER, AND J. K. PETELL \\ Department of Pediatrics, Zöliakieforschungslabor der Autonomen Provinz Bozen, Südtirol, \\ 39100 Bozen, Italy [K.P., B.L.], and Biotechnology Department, DowElanco, Indianapolis, \\ Indiana 46268 [J.K.P.]
}

\section{ABSTRACT}

The binding patterns of gliadin and selected lectins to jejunal biopsy specimens obtained from children with total villous atrophy during active celiac disease (CD; 19 patients) and in remission (16 patients) were examined by light microscopy. Three categories of carbohydratespecific lectins were chosen for the study: those recognizing mannose/glucose residues, those recognizing $\mathrm{N}$-acetylglucosamine/glucose (glcNAc/glc) residues, and those recognizing $\mathrm{N}$-acetylgalactosamine/galactose (galNAc/gal) residues. The galNAc/gal lectins, with the exception of phaseolus vulgaris agglutinin variants, presented a typical staining of the luminal surface of the jejunal mucosa obtained from $C D$ patients. However, these lectins displayed no reactivity to jejunal sections of $\mathrm{CD}$ patients in remission or control biopsies that included healthy children $(25$ children) and patients suffering from cow milk protein allergy (10 children). The glcNAc/glc lectin showed a strong preferential recognition of $\mathrm{CD}$ jejunal tissue but also bound with less intensity to specimens from patients with cow milk allergies and healthy children. Unlike other galNAc/ gal lectins, phaseolus vulgaris agglutinin variants were indistinguishable in their binding patterns to the mucosa of control groups and $\mathrm{CD}$ patients in remission and failed to react to $C D$ biopsies. The mannose/glc lectins were not distinctive in their binding patterns. In all cases, lectin binding was specifically inhibited by the lectins' competitive saccharides. Atypical of lectin binding patterns, gliadin reactivity was restricted to intracellular areas of entero- cytes and was unique to active CD mucosa. The distinctive binding patterns of lectins and gliadin provide a diagnostic tool to distinguish patients with active $C D$ from those in remission or patients with other intestinal disorders. These findings raise interesting questions about the role of gliadin and lectins in CD. It is speculated that the presence of new luminal sites may act to manifest lectin susceptibility and exacerbate CD pathology. (Pediatr Res 36: 635-641, 1994)
Abbreviations
CA III, peptic tryptic casein digest
CD, celiac disease
CMPA, cow milk protein allergy
Con A, concanavalin A
FF III, Frazer's fraction
gal, galactose
galNAc/gal, $\mathrm{N}$-acetylgalactosamine/galactose
glc, glucose
glcNAc/glc, $\mathrm{N}$-acetylglucosamine/glucose
LCA, lens culinaris agglutinin
PHA-E, phaseolus vulgaris erythroagglutinin
PHA-L, phaseolus vulgaris leukoagglutinin
PSA, pisum sativum agglutinin
BSL, bandeiraea simplicifolia leukoagglutinin
SBA, soybean agglutinin
SJA, sophora japonica agglutinin
WGA, wheat germ agglutinin

The pathogenesis of childhood and adult $\mathrm{CD}$ is still not well understood $(1,2)$. CD in childhood is characterized by villous atrophy and an increase in both the number of damaged enterocytes and the cell turnover (3). The precise mechanisms responsible for these changes are still

Received September 16, 1993; accepted March 17, 1994

Correspondence: Klaus Pittschieler, M.D., Pediatric Gastroenterology, L. Böhler Str. 5, 39100 Bozen, Italy.

Supported by grants from the Assessorat für Gesundheitswesen der Autonomen Provinz Bozen.

${ }^{1}$ Abstract accepted from European Society for Paediatric Gastroenterology and Nutrition in March 1991 for oral presentation at the annual meeting. controversial (4); however, most investigators believe that local immunologic reactions are involved and that gluten initiates the process in an unknown way (5). The basis for gliadin involvement stems from reports that gliadin, a complex heterogeneous protein in gluten of wheat, barley, rye, and possibly oats, binds to smallintestinal surface elements (6). A similar hypothesis for lectin-like involvement of gluten in $\mathrm{CD}$ was suggested by Weiser and Douglas (7), who indicated that gluten might have a lectin-like activity against intestinal epithelium in $\mathrm{CD}$. The interaction of gliadin with the intestinal mucosa of patients with CD had already been described in 1965 
(8). Rubin et al. (8) showed by immunofluorescent studies in adult $\mathrm{CD}$ patients that gliadin accumulates in the cytoplasm of epithelial cells during active CD. Furthermore, it was reported that an abnormal glycoprotein in the brush-border membrane was present in the jejunal mucosa of CD patients observed to have an increased gluten adherence (9). Thus, gliadin peptides were proposed to have lectin-like effects that could explain their pathogenic role in $\mathrm{CD}$ (7). The exact mechanism by which these peptides cause gut damage is unknown; however, peptidase deficiency, an immune defect, or lectin-like properties leading to a reaction between the cell surface membrane carbohydrate components and gliadin have been proposed, connecting genetic, biochemical, and immunologic theories (10). Immune reactions to gliadin are likely to play a role in the pathogenesis of the disease, inasmuch as both humoral and cellmediated responses have been demonstrated in the peripheral blood and in the gut of patients with $C D$.

The precise role of gliadin as a lectin remains controversial; several investigators have conflicting reports on the binding properties of FF III, a peptic-tryptic digest fraction of gliadin, to specific sugar moieties and their effect in culture on tissue epithelium $(6,11-15)$.

The aim of the present work was 1 ) to extend the observations of earlier studies by examining the reaction of various lectins on the jejunal biopsy specimens from children with active $\mathrm{CD}$, children with $\mathrm{CD}$ in remission, healthy children, and children suffering from CMPA, and 2) to analyze the binding behavior of gliadin and its digest fractions to enterocytes or intraepithelial lymphocytes to elucidate whether the hypothesis of lectin-like properties of gliadin as the pathogenetic factor of $\mathrm{CD}$ is still fashionable by the actual state of knowledge.

\section{METHODS}

Specimens. Small-intestinal biopsies were obtained with a pediatric Watson biopsy capsule near the ligament of Treitz under fluoroscopic control in four groups of patients.

Group A: Nineteen patients (10 females and nine males) ranging in age from 1.5 to $2.5 \mathrm{y}$ had untreated $\mathrm{CD}$ with total mucosa atrophy. At time of the first biopsy, the patients had never been on a gluten-free diet. The diagnosis has been subsequently verified according to ESPGAN criteria.

Group B: Sixteen patients (10 females and six males), from 3 to $12 \mathrm{y}$ old, had previously been treated for $\mathrm{CD}$. They had a jejunal mucosa histologically indistinguishable from normal mucosa after dietary restriction of gluten. The diagnosis of CD had been demonstrated previously according to the European Society for Paediatric Gastroenterology and Nutrition criteria.

Group C: Twenty-five children (15 females and 10 males) ranging in age from 2 to $5 \mathrm{y}$ investigated for growth retardation and bearing a normal jejunal mucosa were used as controls.
Group D: A second control group was represented by 10 children (three females and seven males) ranging in age from 2 to 6 mo affected by CMPA showing partial villous atrophy and diagnosed by food challenge.

Tissue preparation. For paraffin sections immediately after excision, biopsy specimens were fixed in $10 \%$ formalin, dehydrated, and embedded in paraffin. Sections, 4 $\mu \mathrm{m}$ thick, were cut, deparaffinized in xylol, rehydrated in graded ethanol solutions, washed in distilled water, and subsequently washed in $0.01 \mathrm{M}$ PBS, pH 7.4. To block the endogenous peroxidase, sections were incubated in $0.3 \% \mathrm{H}_{2} \mathrm{O}_{2}$ in methanol for $20 \mathrm{~min}$.

For frozen sections, biopsy specimens obtained from patients of the four groups were embedded in OCT (Miles, Bayer, Milano, Italy) and quick-frozen in liquid nitrogen, and 4- $\mu$ m-thick sections were cut using a cryostat microtome. After air drying, sections were fixed in acetone at $-20^{\circ} \mathrm{C}$ for $10 \mathrm{~min}$, dryed again for $30 \mathrm{~min}$, and subsequently washed with PBS.

Preparation of gliadin and casein digest. A peptic-tryptic digest of gliadin (FF III) and casein (CA III), provided by H. Wieser, Ph.D. (Deutsche Versuchsanstalt für Lebensmittelchemie, Munich, Germany), was prepared in the following way: For gliadin extraction, $200 \mathrm{~g}$ of wheat (Kolibri 630) were defatted with petrol ether and dried on filter paper. Fifty grams of the flour were dissolved three times in $0.4 \mathrm{M} \mathrm{NaCl}$. After low-speed centrifugation, the supernatants were collected, dialyzed against acetic acid, and lyophilized. Ten grams of gliadin or casein and $50 \mathrm{mg}$ of pepsin were added to $100 \mathrm{~mL}$ of $0.2 \mathrm{~N} \mathrm{HCl}$ and hydrolyzed for $4 \mathrm{~h}$. Thereafter, the $\mathrm{pH}$ was adjusted to 7.8 . The hydrolysis was continued for $4 \mathrm{~h}$ at $37^{\circ} \mathrm{C}$ by $50 \mathrm{mg}$ of trypsin. After the $\mathrm{pH}$ was adjusted to 4.5 , the preparation was ultracentrifuged and lyophilized.

Biotinylation of gliadin and casein digests. A solution of $\mathrm{N}$-hydroxy-succinimide biotin $(10 \mathrm{mg} / \mathrm{mL})$ was prepared in DMSO. Biotin ester was added in a ratio of $250 \mathrm{mg} / \mathrm{mg}$ protein to solutions of FF III $(4 \mathrm{mg} / \mathrm{mL})$ or CA III $(4$ $\mathrm{mg} / \mathrm{mL}$ ) in $0.1 \mathrm{M}$ sodium borate, $\mathrm{pH} 8.8$, and incubated at room temperature for $4 \mathrm{~h}$. Afterward, $20 \mathrm{~mL}$ of $1 \mathrm{M}$ $\mathrm{NH}_{4} \mathrm{Cl}$ was added per $250 \mathrm{mg}$ of ester and incubated for $10 \mathrm{~min}$ at room temperature. Samples were dialyzed against PBS and stored at $-20^{\circ} \mathrm{C}$ until used.

Lectin histochemistry. Lectins selected for study included WGA, Con A, SBA, PHA-L, PHA-E, SJA, PSA, BSL 1, and LCA. Lectin concentrations were 1.0 or 2.5 $\mu \mathrm{g} / \mathrm{mL}$ (WGA, Con A, and SBA) and 0.8 or $1.6 \mu \mathrm{g} / \mathrm{mL}$ (PHA-E, PHA-L, SJA, PSA, BSL 1, and LCA) for frozen or paraffin sections, respectively.

Nonspecific binding to formalin- or acetone-fixed sections was performed by preincubation with $2 \%$ BSA (Ortho Diagnostic System, Milano, Italy) for $20 \mathrm{~min}$ followed by incubation for $1 \mathrm{~h}$ at room temperature in a moist chamber with biotinylated lectins (Vector Laboratories, Burlingame, CA) or with PBS to determine the reactivity of the different chemicals used. After being washed, sections were incubated with avidin-biotinhorseradish peroxidase complex (ABC kit, Dakopatts, 
Glostrup, Denmark) followed by aminoethylcarbazole as the substrate (AEC kit, Dakopatts). After counterstaining with Mayer's hematoxylin, specimens were mounted with mounting medium (Ortho Diagnostic System) and observed by light microscope. The results were overviewed by two different researchers.

Histologic staining with gliadin and biotinylated protein digests. Crude gliadin was dissolved in $0.05 \mathrm{M}$ Tris $(\mathrm{pH}$ 8.5 ) with $2 \mathrm{M}$ urea at a concentration of $12 \mathrm{mg} / \mathrm{mL}$. The formalin-fixed sections were covered with goat normal serum (diluted 1:5) for $20 \mathrm{~min}$ for reduction of nonspecific staining. Sections were incubated with gliadin for $1 \mathrm{~h}$, and, after washing them in PBS, specimens were incubated at $4^{\circ} \mathrm{C}$ overnight with antigliadin rabbit antibodies (working dilution 1:2000). Sections were washed twice in PBS and reacted with biotinylated goat-to-rabbit IgG and with avidin-biotin-horseradish peroxidase complex. Sections were mounted and viewed as described above. Additional specimens were treated the same way with BSA dissolved in the same buffer as gliadin but without gliadin incubation or with gliadin but without the specific primary antigliadin antibody (negative controls).

To investigate the possible role of urea in modifying tissue properties and thus the binding patterns of different lectins, we solubilized lectins as they were used in gliadin experiments in similar amounts of urea $(2 \mathrm{M})$.

For biotinylated protein digests, jejunal specimens were incubated, after pretreatment, according to the lectin histochemistry for $1 \mathrm{~h}$ with biotinylated FF III and CA III at concentrations of $4 \mathrm{mg} / \mathrm{mL}$ and $1 \mathrm{mg} / \mathrm{mL}$ for paraffin and frozen sections, respectively. Sections were washed, then stained for peroxidase activity as described above and viewed.

Immunohistochemical staining with anti-human $\operatorname{Ig} A, \operatorname{Ig} G$, and IgM antibodies. Formalin-fixed specimens from CD patients and healthy controls were incubated after pretreatment with biotinylated goat anti-human IgA, IgM, and IgG antibodies (concentration: $7.2-10 \mathrm{mg} / \mathrm{mL}$ ) for $1 \mathrm{~h}$, washed with PBS, and processed as described before.

Competition studies with gliadin, lectins, and biotinylated protein digests. For competition studies using paraffin sections, gliadin, lectins, and FF III or CA III were coincubated with monosaccharides $(0.1 \mathrm{M}$ solutions) and the oligosaccharide mannan $(3 \mathrm{mg} / \mathrm{mL})$ for $1 \mathrm{~h}$ at room temperature. Monosaccharides used were glcNAc, gal, rhamnose, arabinose, fucose, or lactose as indicated in Table 1.

Additional control experiments were carried out to prove the specificity of the other experiments: Specimens of the diverse types of jejunal mucosa were preincubated for $1 \mathrm{~h}$ with unconjugated FF III $(12 \mathrm{mg} / \mathrm{mL})$ before the incubation with gliadin to test cross-reactions of gliadin and its digest. Tissues were incubated after BSA treatment with unconjugated FF III, CA III ( $3 \mathrm{mg} / \mathrm{mL}$ PBS), or gliadin $(12 \mathrm{mg} / \mathrm{mL}$ in $2 \mathrm{M}$ urea in $0.05 \mathrm{M}$ Tris, $\mathrm{pH} 8.5)$ for $1 \mathrm{~h}$. After being washed in PBS for $10 \mathrm{~min}$, they were incubated with biotinylated FF III $(3 \mathrm{mg} / \mathrm{mL})$. The specimens were then processed as described before.

All reagents used, if not noted elsewhere, were from Sigma, Milano, Italy.
Table 1. Lectin studied, their sugar specificities, and tested inhibiting and nonspecific carbohydrates*

\begin{tabular}{llll}
\hline \multicolumn{1}{c}{ Lectins } & \multicolumn{1}{c}{$\begin{array}{c}\text { Carbohydrates } \\
\text { specificity }\end{array}$} & $\begin{array}{c}\text { Inhibition } \\
\text { sugars }\end{array}$ & \multicolumn{1}{c}{$\begin{array}{c}\text { Nonspecific } \\
\text { sugars }\end{array}$} \\
\hline WGA & D-glcNAc/glc & GlcNAc & Gal \\
SBA & D-galNAc/gal & Gal & Rham \\
SJA & b-D-galNAc/gal & Gal & Ara \\
BSL 1 & a-D-galNAc/gal & Gal & Fuc \\
PHA-E & D-galNAc/gal & Gal & Rham \\
PHA-L & D-galNAc/gal & Gal & Rham \\
Con A & a-D-man, a-D-glc & Mannan & Ara \\
PSA & a-D-man, a-D-glc & Mannan & Lac \\
LCA & a-D-man, a-D-glc & Mannan & Fuc \\
Gliadin, FF III, & & & Mannan, glcNAc, \\
CA III & & & gal, ara, rham \\
\hline
\end{tabular}

* Rham, rhamnose; ara, arabinose; fuc, fucose; lac, lactose; man, mannose.

\section{RESULTS}

The binding of lectins to specimens from $C D$ patients and controls. The jejunal mucosa from children with active $\mathrm{CD}$, children with $\mathrm{CD}$ in remission, children with CMPA, and normal, healthy children revealed a characteristic binding pattern reflecting the different lectins tested. The composite results are presented in Table 2. No differences were observed in lectin binding patterns using either paraffin or frozen sections of specimens. The sections incubated only with PBS instead of lectins did not show any reactivity.

GalNAc/gal lectins (SBA, SJA, and BSL 1) stained the brush border on the mucosa of CD patients (Fig. 1). No binding was observed in the jejunum of mucosa from control subjects, $\mathrm{CD}$ patients in remission, and children with CMPA. PHA-E and PHA-L lectins displayed a pattern remarkably different from those of other galNAc/ gal lectins by binding to the mucosa of healthy children, $\mathrm{CD}$ patients in remission, patients with active CD (Fig. 2 ), and children with CMPA. The brush border and the luminal surface of the crypt cells in the mucosa of healthy children, children with CMPA, and children treated for $\mathrm{CD}$ were strongly reactive. In contrast, no reaction was shown on the luminal surface of the mucosa from children with active disease. PHA-L and PHA-E also showed sporadic binding to goblet cells and to mucus on tissue from healthy children and patients with active CD.

The glcNAc/glc lectin (WGA) demonstrated the same reactivity as the galNAc/gal lectins, SBA, SJA, and BSL 1 , on the brush border from mucosa of children with active $C D$. This characteristic staining was not evident on mucosa of CD patients in remission, and only a weak reaction could be recorded on the epithelial surface of mucosa from the control groups.

In contrast to the results with other lectins, no preferential staining of the luminal surface of mucosa from normal children, children with CMPA, or CD patients was observed using mannose/glc-specific lectins (LCA, PSA, and Con A). LCA stained goblet cells and mucus in normal specimens and in specimens from $C D$ patients with total villous atrophy. In specimens from $C D$ patients 
Table 2. Lectin and gliadin binding in jejunal specimens*

\begin{tabular}{|c|c|c|c|c|c|c|}
\hline Fraction & $\begin{array}{c}\text { Sugar } \\
\text { specificity }\end{array}$ & Patient & $\begin{array}{c}\text { Brush } \\
\text { border }\end{array}$ & $\begin{array}{c}\text { Cytoplasm of } \\
\text { epithelial surface }\end{array}$ & $\begin{array}{l}\text { Cytoplasm } \\
\text { crypt cells }\end{array}$ & $\begin{array}{c}\text { Goblet } \\
\text { cells }\end{array}$ \\
\hline \multirow[t]{4}{*}{ BSL, SJA, SBA } & GalNAc & $\mathrm{CD}$ & + & - & - & - \\
\hline & & CDR & - & - & - & - \\
\hline & & $\mathrm{H}$ & - & - & - & - \\
\hline & & CMPA & - & - & - & \\
\hline \multirow[t]{4}{*}{ PHA-L and $-E$} & GalNAc & $\mathrm{CD}$ & - & - & - & + \\
\hline & & CDR & + & - & - & - \\
\hline & & $\mathrm{H}$ & + & - & - & + \\
\hline & & CMPA & + & - & - & - \\
\hline \multirow[t]{4}{*}{ WGA } & GlcNAc & $\mathrm{CD}$ & + & - & - & - \\
\hline & & CDR & - & - & - & - \\
\hline & & $\mathrm{H}$ & $+1-$ & - & - & - \\
\hline & & CMPA & $+1-$ & - & - & - \\
\hline \multirow[t]{4}{*}{ PSA } & Man/glu & $\mathrm{CD}$ & - & - & - & - \\
\hline & & $\mathrm{CDR}$ & - & - & - & - \\
\hline & & $\mathrm{H}$ & - & - & - & + \\
\hline & & CMPA & - & - & - & - \\
\hline \multirow[t]{4}{*}{ LCA } & $\mathrm{Man} / \mathrm{glc}$ & $\mathrm{CD}$ & - & - & - & + \\
\hline & & CDR & - & - & - & - \\
\hline & & $\mathrm{H}$ & - & - & - & + \\
\hline & & CMPA & - & - & - & - \\
\hline \multirow[t]{4}{*}{ Con A } & Man/glc & $\mathrm{CD}$ & - & + & - & - \\
\hline & & CDR & - & + & - & - \\
\hline & & $\mathbf{H}$ & - & + & - & - \\
\hline & & CMPA & - & + & - & - \\
\hline \multirow[t]{4}{*}{ Gliadin } & & $\mathrm{CD}$ & - & - & + & - \\
\hline & & CDR & - & - & - & - \\
\hline & & $\mathrm{H}$ & - & - & - & - \\
\hline & & CMPA & - & - & - & - \\
\hline \multirow[t]{4}{*}{ FF III } & & $\mathrm{CD}$ & + & + & + & + \\
\hline & & CDR & - & + & - & - \\
\hline & & $\mathrm{H}$ & - & + & - & - \\
\hline & & CMPA & - & - & - & - \\
\hline \multirow[t]{4}{*}{ CA III } & & $\mathrm{CD}$ & $+/-$ & $+1-$ & $+1-$ & $+1-$ \\
\hline & & CDR & - & $+1-$ & - & - \\
\hline & & $\mathrm{H}$ & - & $+1-$ & - & - \\
\hline & & CMPA & - & - & - & - \\
\hline
\end{tabular}

${ }^{*} \mathrm{CDR}, \mathrm{CD}$ in remission; $\mathrm{H}$, healthy controls; man, mannose. $\dagger$, Reactivity; $+/-$, weak or sporadic reactivity; - , no reactivity.

in remission, a strong reactivity of the basal membrane was observed. PSA stained the basal membrane and goblet cells of sections from healthy children. Con A stained with different intensity cytoplasmatic structures

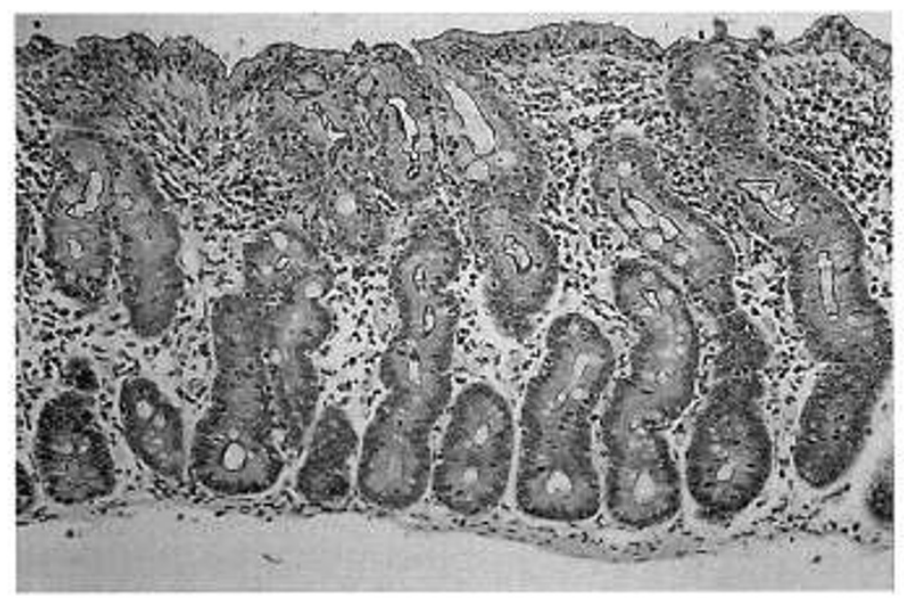

Figure 1. Staining of mucosa from an untreated $\mathrm{CD}$ patient with galNAc lectin. The galNAc/gal-specific lectins BSL, SJA, and SBA stained the brush border of the flat mucosa of CD patients. WGA, the glcNAc/glc-specific lectin, displayed the same reactivity as the galNAcspecific lectins $(200 x)$. of a few enterocytes located on the epithelial surface in the same manner in all four investigated groups (Fig. 3). No reaction was seen in any crypt cells.

Binding of gliadin and FF III to specimens from $\mathrm{CD}$ patients and controls. Gliadin did not show any reaction to jejunal sections from either control subjects, children with

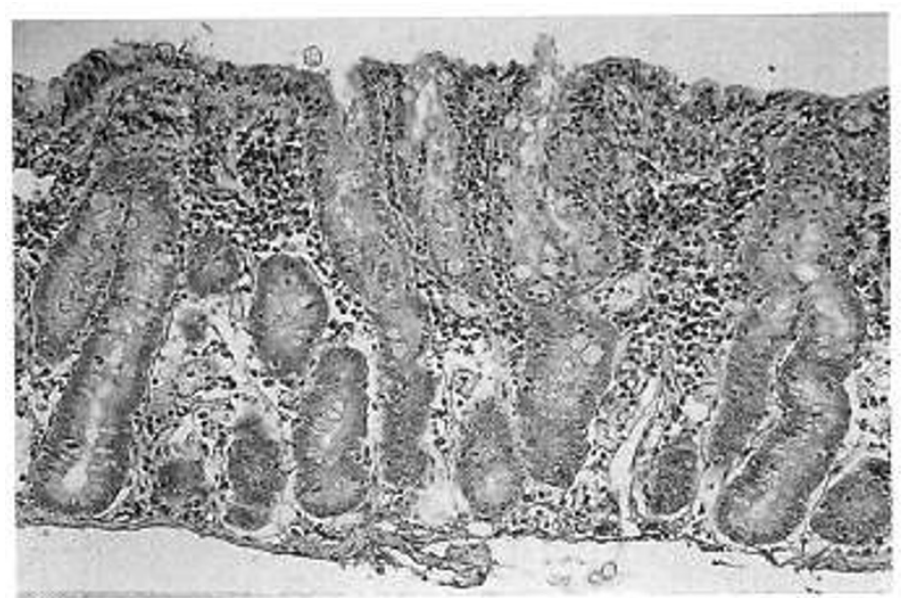

Figure 2. Staining of mucosa from a control patient with PHA-E. PHA-E and PHA-L showed sporadic binding to goblet cells and mucus on tissue from children with active CD $(200 \times)$. 


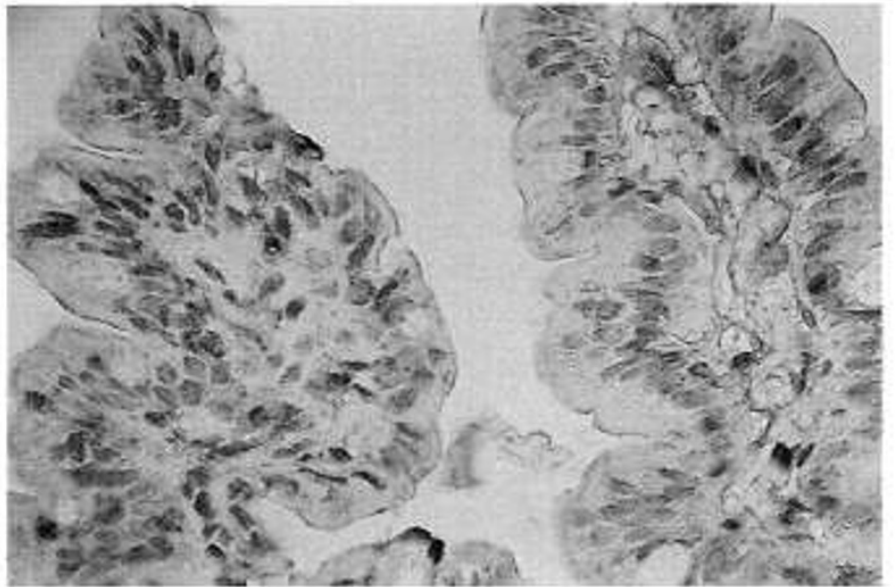

Figure 3. Con A staining of enterocytes from healthy controls. Con A stained cytoplasmatic structures of enterocytes located on the tip of villi in the two control groups, $\mathrm{CD}$ patients in remission, and enterocytes of the flat CD mucosa $(800 \times)$.

CMPA, or CD patients in remission. In contrast, gliadin binding was observed only inside the cytoplasm of epithelial cells in the crypts of tissue from children with active $\mathrm{CD}$ (Fig. 4). The incubation of the jejunal CD mucosa in urea-solubilized BSA did not reveal any reaction, ruling out an unspecific staining of the cytoplasm by gliadin.

FF III stained throughout the structures (epithelial and nonepithelial) of the flat $\mathrm{CD}$ mucosa. In CD patients in remission and healthy controls, we noted binding of $\mathrm{FF}$ III in the cytoplasm only in those enterocytes located on the villous surface. The binding patterns observed for FF III were always similar to those of CA III, although the latter displays a less intensive staining in the cytoplasm of $\mathrm{CD}$ in remission. The FF III binding was never inhibited by CA III.

Gliadin and its peptic-tryptic digest did not bind to the mucosa of patients with CMPA.

Because the solubilization of lectins in urea or PBS did not affect their binding patterns, we must conclude that,

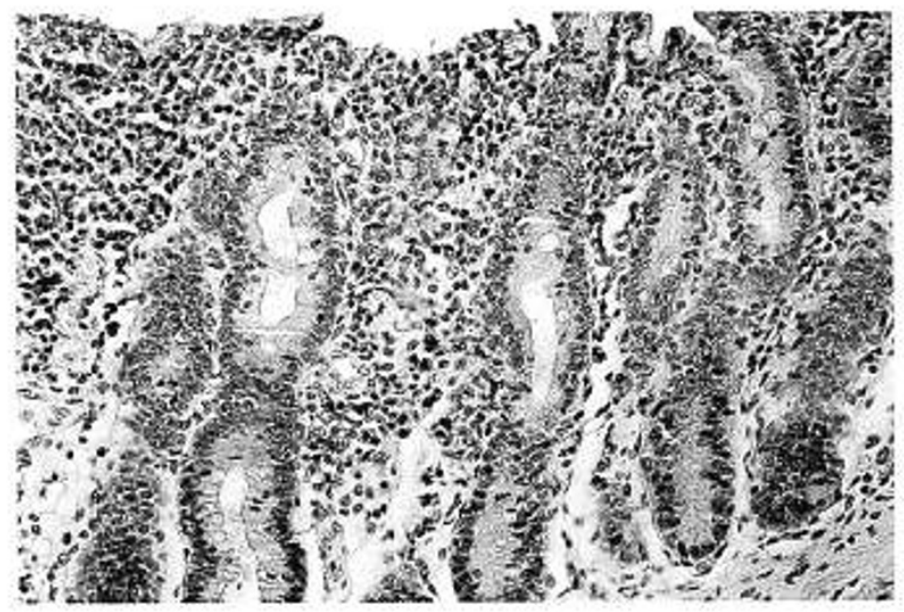

Figure 4. Gliadin staining of crypt enterocytes from active $C D$ patients. The staining reaction in the cytoplasm of enterocytes within crypt cells of jejunal mucosa from children with active $C D$ was unique for gliadin $(400 \times)$. similarly, the use of urea in dissolving gliadin might not affect our data.

Competition studies for lectins and gliadin by specific sugars. The binding reaction of all tested specific lectins was inhibited by the presence of competing carbohydrates but not by nonspecific sugars in all four groups. The staining of the cytoplasm by gliadin, FF III, or CA III was not influenced by monosaccharides or oligosaccharides.

The preincubation of the specimens with FF III before applying gliadin did not show any effect on the reactivity of gliadin. Similarly, preincubation with gliadin did not inhibit the FF III staining reaction. Unconjugated FF III alone could inhibit the binding of biotinylated FF III to the mucosa.

Immunhistochemistry with anti-human $\operatorname{IgG}, \operatorname{Ig} A$, and IgM antibodies. As controls, specimens from $C D$ patients and healthy children were incubated with anti-human IgA, IgM, and IgG antibodies to evaluate whether the observed gliadin binding was due to endogenous antigliadin-specific Ig. We noticed in tissues from patients with active $C D$ a higher ratio of IgG-, IgA-, and IgMproducing B cells. Particulary IgA-bearing lymphocytes and, less pronouncedly, IgM-bearing lymphocytes were distinguished in higher concentration in the upper part of the lamina propria (Fig. 5). The tissue of CD patients in remission, although still showing a higher ratio of IgG-, IgA-, and IgM-producing plasma cells in contrast to normal children, was characterized by a typical distribution pattern of B cells sparing the lamina propria of the tip of the villi.

\section{DISCUSSION}

Lectins interact with cell surface carbohydrates in a way that distinguishes them from other carbohydratebinding proteins, which include carbohydrate-specific antibodies, enzymes, and hormones. Their binding to exposed complementary sugar sites on the cell surface is not significantly influenced by side interactions (16). Lec-

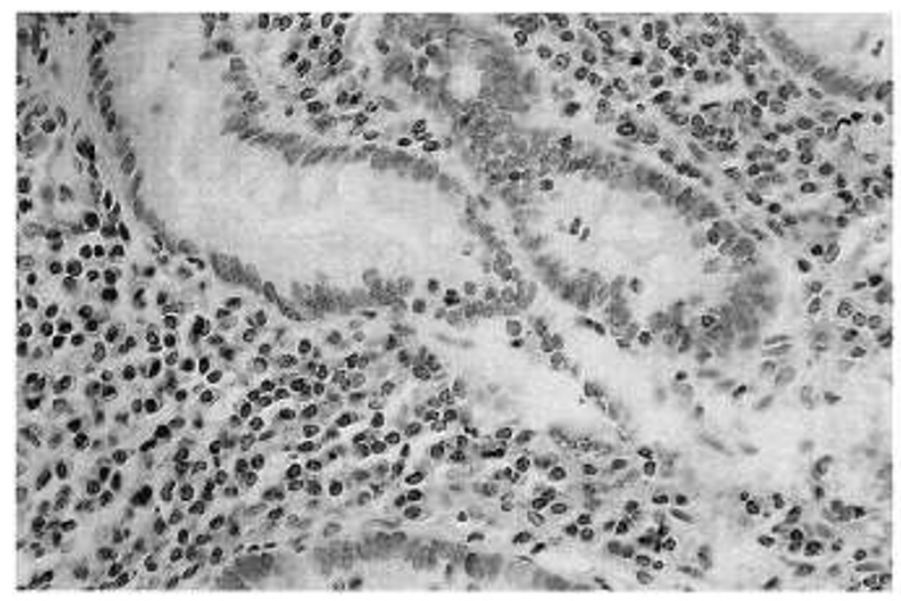

Figure 5. IgA-producing B lymphocytes in the mucosa of patients with active $C D$. The lamina propria of the flat mucosa of $C D$ patients displayed an increased number of IgA-producing plasma cells $(800 \times)$. 
tins can cause different biologic effects in vitro such as precipitation of polysaccharides; agglutination of erythrocytes, bacteria, and tumor cells; and lymphocyte transformation (17). In the animal model, gold-conjugated Con A administered directly into the jejunum will result in the disruption of mucosal integrity as indicated by an increased permeability and uptake by both villous and crypt cells identifying specific glycoprotein receptors in the neonatal microvillus membrane (18). The uptake is thought to occur by receptor-mediated endocytosis (19). WGA- and Con A-induced changes in small-intestinal enterocytes can be prevented by the addition of competing sugars, glcNAc and mannan, respectively, leading to the conclusion that alterations were produced by a cell surface receptor-lectin interaction rather than by a primary intracellular effect (20). One pathogenic hypothesis suggests that gluten could bind to altered and incomplete exposed cell surface membrane glycoproteins and act as a toxic lectin, leading to structural changes of the intestinal mucosa (7). In the animal model, however, it seems likely that the binding of gliadin to the luminal surface is a nonspecific event (21).

Although reports indicative of a putative gliadin receptor on peripheral lymphocytes have been published, the proof of the presence of an epithelial receptor in the small intestine remains elusive $(22,23)$.

Changes in intestinal surface carbohydrates are recognized to occur during processes of maturation or abnormal differentiation of epithelial cells in the smallintestinal epithelium. The addition and rearrangement of glycoprotein carbohydrate side chains is regulated by different glycosyltransferase enzymes whose activity has been shown to be strictly related to the cell maturity and state of differentiation. It was thought that gluten-induced epithelial cell death and increased cell turnover is followed by incomplete cell maturation in the small intestine of patients with $\mathrm{CD}$, thereby generating an augmentation of gluten binding sites and exacerbating the offensive effects of gliadin and probably lectins (24-27).

In our experiments, three sugar-specific categories of lectins were assessed for binding to the mucosa in patients with active $C D$, patients with $C D$ in remission, children with CMPA, and healthy controls. Each of the lectin groups, mannose/glc (Con A, PSA, and LCA), galNAc/gal (SBA, SJA, BSL 1, PHA-E, and PHA-L), and glcNAc/glc (WGA), displayed a distinct and unique binding pattern to normal and diseased mucosa. The galNAc/gal- and glcNAc/glc-specific lectins had a similar pattern on the mucosa, binding to the brush border of the jejunal mucosa from children with active $C D$, except for PHA-E and PHA-L, which bound to the mucosa from healthy children, children with CMPA, and children with $\mathrm{CD}$ in remission. The most intriguing staining patterns are those of Con $\mathrm{A}$. It has been published that this lectin at a higher local instillation rate in vivo in postclosure guinea pigs is able to increase not only gastrointestinal permeability by disruption of the mucosal integrity but also the crypt cell production rate and finally provoke a dispersal of the lectin throughout the cytoplasm of both villous and crypt epithelial cells $(18,19)$. Similarly, our experiments showed an augmentation of the permeability through microvillus membranes into the cellular cytoplasm in vitro more or less in all four investigated mucosa groups. The glcNAc/glc-specific lectin WGA showed the same reactivity as the galNAc/gal-specific lectins. Because lectins can have differential binding specificities, the binding to complex carbohydrates of glycoproteins may be very different from the binding specificity to purified monosaccharides (28). PSA and LCA showed a high affinity just to goblet cells and mucus. Although the lectin binding sites are mostly localized at the luminal cell membrane, the binding of gliadin was localized to intracellular areas and was unique to active CD mucosa. More importantly, mucosa of $\mathrm{CD}$ patients in remission did not show any reaction with gliadin. These results are in agreement with data from organ culture, where the $C D$ control mucosa in remission showed no signs of impairment after gluten exposure in vitro (29). The gliadin digest, FF III, displays (probably in relation to the enzymatic cleavage) a specific cytoplasmatic staining behavior, reacting solely in healthy enterocytes (children with $\mathrm{CD}$ in remission and healthy controls) but not accumulating or binding in a specific manner to cytoplasmatic structures in highly damaged cells as in those of children with active $\mathrm{CD}$ and CMPA.

Our results suggest that the reactivity of gliadin is not related to a specific inborn abnormality of a putative receptor. Furthermore, we speculate that the presence of new galNAc and glcNAc target sites on the luminal surface may exacerbate the disease by allowing lectinassociated insults to the mucosal integrity. Along similar lines, Falchuk et al. (30) suggested that gluten peptides are not directly toxic to epithelial cells of celiac mucosa but require the activation of an endogenous effector that is diffusible through the culture medium. The effector induces the dedifferentiation of enterocytes of intestinal mucosa to a stage that is more susceptible to direct toxic effects of gliadin peptides $(30,31)$. These unknown effects are probably related to the cellular and humoral immunity. Thus, CD could be regarded as a disorder initiated in genetically predisposed individuals by an undefined trigger in which the immune response, perpetuated by ingested gluten, leads to organ-specific tissue damage $(32,33)$. Increased numbers of IgA- and IgM-secreting plasma cells in the lamina propria of the mucosa of CD patients compared with healthy children and the return to normal features with treatment are indicative of an immunity-associated disease (34). Similarly, the intraepithelial infiltration of $\mathrm{CD} 8^{+} \mathrm{T}$ lymphocytes and the increased proportion of $\mathrm{CD}^{+} \mathrm{T}$ cells expressing the $\gamma / \delta$ receptor in $\mathrm{CD}$ patients suggest that the tissue damage occurs as a consequence of the immune response $(35,36)$.

In conclusion, we postulate based on our observations that the adverse effects of gliadin on celiac epithelial cells occur after an unknown initial event, perhaps affecting their state of differentiation in association with the immu- 
nity, which acts to render the celiac mucosa susceptible to gliadin elements. A viral infection by adenovirus 12 has been invoked to initiate the events by triggering the immune response to the normally tolerated gliadin (37). This subtle but dramatic alteration in cellular components is verified by gliadin binding only in CD patients and not in patients in remission or in damaged mucosa from children with CMPA. To restate the premise, it seems logical that if enterocytes of CD patients in remission contain a putative gliadin receptor it is expected that gliadin should bind significantly. No gliadin binding was observed.

Conversely, lectins showed differential binding in all four tissue groups. Furthermore, no common lectinbinding properties were observed for tissues of $\mathrm{CD}$ patients or children with $\mathrm{CD}$ in remission. In short, we believe that the role of lectins as the principle agent of the disease is questionable because they exhibit their own specific reactions, which could in all of them (Con A included) be inhibited in competition studies by their specific sugars. In the literature, WGA has been suspected to contaminate pure gliadin preparation and consequently influence the behavior of gliadin on the CD mucosa (14); from our data, it is evident that gliadin and the lectin WGA have different activities. Furthermore, there is no evidence from the mucosal binding behavior of gliadin to confirm that this glycoprotein works in a lectin-like manner (38).

The two distinct clinical pictures of CMPA and CD also show on a cellular basis different and specific binding abilities, inasmuch as we could demonstrate that mucosa damaged by CMPA is not prone to exhibit staining patterns similar to those of enterocytes from active CD after incubation with lectins and gliadin.

After almost $30 \mathrm{y}$ of intensive research on the pathogenesis of $\mathrm{CD}$ focusing on the clandestine effect of gliadin and lectins, based on our data we can state that the wheat-derived antigens of gluten have a non-lectin-like presentation to the enterocytes and intestinal mucosal immune system.

Acknowledgments. The authors thank H. Wieser H., Ph.D., from the Deutsche Versuchsanstalt für Lebensmittelchemie, Munich, Germany, for the preparation of the Frazer's fraction III. We also thank the Department of Pathology of the Regional Hospital in Bozen for technical assistance.

\section{REFERENCES}

1. Lebenthal E, Branski D 1981 Childhood celiac disease. A reappraisal. J Pediatr 98:681-690

2. Cole SG, Kagnoff MF 1985 Celiac disease. Ann Rev Nutr 5:241-266

3. Shiner M 1984 Present trends in coeliac disease. Postgrad Med J 60:773-778

4. Köttgen E 1986 Neue Aspekte zur Gluten-sensitiven Enteropathie. Internist 27:656-664

5. Strober W $1978 \mathrm{An}$ immunological theory of gluten-sensitive enteropathy. In: McNicholl B, McCarthy CF, Fortell PF (eds) Perspectives in Celiac Disease. University Park Press, Baltimore, pp 169-182

6. Köttgen E, Volk B, Kluge F, Gerok W 1982 Gluten, a lectin with oligomannosyl specificity and the causative agent of gluten-sensitive enteropathy. Biochem Biophys Res Commun 109:168-173
7. Weiser MM, Douglas AP 1976 An alternative mechanism for gluten toxicity in coeliac disease. Lancet 13:567-569

8. Rubin W, Fauci AS, Sleisenger MH, Jeffries GH 1965 Immunofluorescent studies in adult celiac disease. J Clin Invest 44:475-485

9. Douglas AP 1976 The binding of a glycopeptide component of wheat gluten to intestinal mucosa of normal and coeliac human subjects. Clin Chim Acta $73: 357-361$

10. Auricchio S, De Ritis G, De Vincenzi M, Silano V 1985 Toxicity mechanisms of wheat and other cereals in celiac disease and related enteropathies. J Pediatr Gastroenterol Nutr 4:923-930

11. Auricchio S, De Ritis G, De Vincenzi M, Magazzu G, Maiuri L, Mancini E, Minetti M, Sapora O, Silano V 1990 Mannan and oligomers of $\mathrm{N}$-acetylglucosamine protect intestinal mucosa of celiac patients with active disease from in vitro toxicity of gliadin peptides. Gastroenterology 99:973-978

12. Auricchio S, De Ritis G, De Vincenzi M, Latte F, Maiuri L, Pino A, Raia V, Silano V 1987 Prevention by mannan and other sugars of in vitro damage of rat fetal small intestine induced by cereal prolamin peptides toxic for human celiac intestine. Pediatr Res 22:703-707

13. Colyer J, Kumar PJ, Waldron NM, Clark ML, Farthing MJG 1987 Gliadin binding to rat and human enterocytes. Clin Sci 72:593-598

14. Kolberg J, Sollid L 1985 Lectin activity of gluten identified as wheat germ agglutinin. Biochem Biophys Res Commun 130:867-872

15. Rawcliffe PM, Priddle JD, Jewell DP 1985 Coeliac disease: possible mannosespecific lectin activity of gluten. Clin Sci 69:11

16. Goldstein IJ, Hayes CE 1978 The lectins: carbohydrate-binding proteins of plants and animals. In: Tipson RS, Horton D (eds) Advances in Carbohydrate Chemistry and Biochemistry. Academic Press, New York, pp 127-340

17. Lis H, Sharon N 1973 The biochemistry of plant lectins (phytohemagglutinins). Annu Rev Biochem 42:541-575

18. Weaver LT, Bailey DS 1987 Effect of the lectin concanavalin A on the neonatal guinea pig gastrointestinal mucosa in vivo. J Pediatr Gastroenterol Nutr 6:445-453

19. Willingham MC, Pastan I 1983 Formation of receptosomes from plasma membrane coated pits during endocytosis: analysis by serial sections with improved membrane labeling and preservation techniques. Proc Nat Acad Sci USA 80:5617-5621

20. Lorenzsonn V, Olsen WA 1982 In vivo responses of rat intestinal epithelium to intraluminal dietary lectins. Gastroenterology $82: 838-848$

21. Stern M, Gellermann B, Belitz HD, Wieser H 1988 Food proteins and maturation of small intestinal microvillus membranes (MVM). II. Binding of gliadin hydrolysate fractions and of the gliadin peptide B3142. J Pediatr Gastroenterol Nutr 7:122-127

22. Verkasalo M 1982 Adherence of gliadin fractions to lymphocytes in coeliac disease. Lancet 1:1384-1386

23. Stern M 1985 Concepts in coeliac disease: is there a receptor for gliadin? Klin Padiat 197:349-354

24. Rubin W, Ross LL, Sleisenger MH, Weiser E 1966 An electron microscopy study of adult celiac disease. Lab Invest 15:1720-1747

25. Phelps CF1978 Biosynthesis of mucus glycoprotein. Br Med Bull 34:43-48

26. Kim YS, Isaacs R, Perdomo JM 1974 Alteration of membrane glycopeptides in human colonic adenocarcinoma. Proc Natl Acad Sci USA 71:4869-4873

27. Kim YS, Perdomo J, Ochoa P, Isaacs RA 1975 Regional and cellular localization of glycosyltransferases in rat small intestine. Changes in enzymes with differentiation of intestinal epithelial cells. Biochim Biophys Acta 391:39-50

28. Monsigny M, Roche AC, Sena C, Magnet-Dana R, Delmotte F 1983 Sugarlectin interactions: how does wheat germ agglutinin bind sialoglycoconjugates? Eur J Biochem 104:147-153

29. Fluge G, Aksnes L 1981 Morphological and morphometric assessment of human duodenal biopsies maintained in organ culture. In vitro influences of gluten in coeliac disease. Scand J Gastroenterol 16:555-567

30. Falchuk ZM, Gebhard RL, Ströber W 1974 The pathogenesis of gluten sensitive enteropathy (celiac sprue): organ culture studies In: Hekkens WTJM, Pena AS (eds) Coeliac Disease. Proceedings of the 2nd International Symposium, Stenfert Kroese, Leiden, pp 107-117

31. Auricchio S, Cardelli M, De Ritis G, De Vincenzi M, Latte F, Silano V 1984 An in vitro animal model for the study of cereal components toxic in celiac disease. Pediatr Res 18:1372-1378

32. Kagnoff M 1989 Immunopathogenesis of celiac disease. Immunol Invest $18: 499-508$

33. Mantzaris GJ, Rosenberg WMC, Jewell DP 1990 The immunology of coeliac disease. Springer Semin Immunopathol 12:219-229

34. Scott BB, Goodall A, Stephenson P, Jenkins D 1984 Small intestinal plasma cells in coeliac disease. Gut 25:41-46

35. Savilahti E, Arato A, Verkasalo M 1990 Intestinal gamma/delta receptor bearing T-lymphocytes in celiac disease and inflammatory bowel disease in children. Constant increase in celiac disease. Pediatr Res 28:579-581

36. Holm K, Mäki M, Savilahti E, Lipsanen V, Laippala P, Koskimies S 1992 Intraepithelial gamma/delta T-cell receptor lymphocytes and genetic susceptibility to coeliac disease. Lancet 339:1500-1503

37. Kagnoff MF 1989 Celiac disease: adenovirus and alpha gliadin. Curr Top Microbiol Immunol 145:67-78

38. Colyer J, Farthing MJG, Kumar PJ, Clark ML, Ohannesian AD, Waldron NM 1986 Reappraisal of the "lectin hypothesis" in the aetiopathogenesis of coeliac disease. Clin Sci 71:105-110 